\title{
Typological Profiles of Depression of College Students: Latent Classes and Controlling for Response Bias of the Baptista Depression Short-Scale (EBADEP-short)
}

\author{
Felipe Valentini ${ }^{1}$ \\ Makilim Nunes Baptista ${ }^{1}$ (D) \\ Nelson Hauck-Filho
}

\begin{abstract}
Response styles and non-linearity might reduce the validity of scores on depression inventories. To address both issues, we explored the latent class structure of the Baptista's Depression Scale (EBADEP), and the influence of extreme response bias. In total, 1,137 Brazilian college students $(M=26$ years, $S D=7.3)$ participated in this study. Taxometric analysis yielded ambiguous results, without clear support for either a dimensional or a categorical representation of the data. We found three latent classes: one comprising participants with a tendency to endorse items about sadness, angst, pessimism, and low self-efficacy; another with individuals scoring low on all symptoms; and a third with intermediate scores. We found no relationship between the composition of latent classes and extreme response. Participants who reported having received a diagnostic of depression were more likely to belong to the first latent class. These findings validate the clinical usefulness of a latent class structure for the EBADEP.
\end{abstract}

Keywords: affective disorders, test bias, depression, psychological assessment, psychological testing

\section{Perfis Tipológicos de Depressão de Universitários: Classes Latentes e Controle de Viés de Resposta da Escala Reduzida Baptista de Depressão - (EBADEP-short)}

\begin{abstract}
Resumo: Respostas extremas e ausência de linearidade podem reduzir a validade de escores de depressão. Para abordar esse problema, este estudo teve por objetivo explorar a estrutura de classes latentes da Escala Baptista de Depressão (EBADEP) e a influência do viés de respostas extremas. Participaram 1.137 estudantes universitários brasileiros $(M=26$ anos, $D P=7,3)$. A análise taxométrica indicou resultados ambíguos, sem um ajuste explicitamente melhor para uma estrutura dimensional ou categórica. Foram identificadas três classes latentes: a primeira, composta de participantes que tenderam a endossar itens de tristeza, angústia, negativismo e baixa autoeficácia; a segunda, de indivíduos com níveis baixos de sintomas; a terceira, com escores intermediários nos itens. Não foram encontradas relação entre as classes latentes e o estilo de respostas extremas. Participantes que relataram um diagnóstico de depressão apresentaram maior probabilidade de pertencer à primeira classe latente. Os resultados evidenciam a utilidade clínica da estrutura de classes latentes para a EBADEP.
\end{abstract}

Palavras-chave: transtornos do humor, viés do teste, depressão, avaliação psicológica, testes psicológicos

\section{Tipología de la Depresión de Estudiantes Universitarios: Clases Latentes y Control del Sesgo de Respuesta de la Escala Reducida Baptista de Depresión (EBADEP-short)}

\begin{abstract}
Resumen: Las respuestas extremas y la falta de linealidad pueden reducir la validez de los escores de depresión. Al abordar este problema, este estudio pretende explorar la estructura de clases latentes de la Escala de Depresión Baptista (EBADEP) y la influencia del sesgo de respuesta extremo. Participaron 1.137 universitarios brasileños $(M=26$ años, $D E=7,3)$. El análisis taxométrico indicó resultados ambiguos, sin un ajuste explícitamente mejor para una estructura dimensional o categórica. Se identificaron tres clases latentes: la primera, compuesta por participantes que tendían a obtener altas puntuaciones en los ítems tristeza, angustia, negativismo y baja autoeficacia; la segunda, de individuos con bajos niveles de síntomas; y la tercera, con puntuaciones intermedias en los ítems. No se encontró relación entre las clases latentes y el estilo de respuestas extremas. Los participantes que informaron estar con diagnóstico de depresión tenían más probabilidades de pertenecer a la primera clase latente. Los resultados muestran la utilidad clínica de la estructura de clases latente para EBADEP.
\end{abstract}

Palabras clave: trastornos afectivos, sesgo, depresión, evaluación psicológica, tests psicológicos

${ }^{1}$ Universidade São Francisco, Campinas-SP, Brazil

Authors receive a scholarship for productivity from CNPq.

Correspondence address: Felipe Valentini, Universidade São Francisco. Rua Waldemar César da Silveira, 105, Jardim Cura D'Ars, Campinas-SP, Brazil. CEP 13.045-510. Email: valentini.felipe@gmail.com
Currently, depression can be considered as one of the most prevalent expression of psychopathology. Approximately 320 million people worldwide, or 5\% of the population, are affected by this disorder, which is often underdiagnosed. Additionally, depression is associated with 
disabilities, affecting personal life, social relationships, and work, causing suffering in those with clinical symptoms (Pelletier, O'Donnell, Dykxhoorn, McRae, \& Patten, 2017; World Health Organization [WHO], 2017).

Depressive syndrome is composed of a heterogeneous set of symptoms that differ from the normal functioning pattern of an individual according to how frequently, long, and intensely they occur. It should be emphasized that current nosographic manuals do not always cover all the behavioral, cognitive, and affective expressions of depression (Zimmerman, Ellison, Young, Chelminski, \& Dalrymple, 2015). Therefore, psychometric scales have been widely used and can also deepen the understanding of the structure of depression (Fried, Epskamp, Nesse, Tuerlinckx, \& Borsboom, 2016). In this study, we explored the possible existence of latent profiles of depression in college students, based on the Baptista Depression Scale - EBADEP (Baptista \& Carvalho, 2018).

Depression is a phenomenon with a complex and heterogeneous structure. As indicated by Fried and Nesse (2015), according to the Diagnostic and Statistical Manual of Mental Disorders (DSM-5), depression symptoms embrace hundreds of combinations. In a sample of 3,700 patients with depression, the authors found 1,030 possible expressions of symptoms, which may reflect etiological heterogeneity, covering several risk factors and associated biomarkers. When two people have the same pattern of signs and symptoms, this does not mean that they will exhibit the same clinical course (Monroe \& Anderson, 2015). Moreover, several people may present symptoms of depression without meeting the criteria for a categorical diagnosis. In other words, symptoms may express a subsyndrome, early detection of which may aid prognosis and interventions (Solomon et al., 2001). For example, van Lang et al. (2006) investigated approximately 3,000 adolescents and concluded that, even in large samples, there are few individuals who present depression exactly as described in the nosography manuals. Thus, identifying classes, or profiles, associated with the symptoms may support diagnoses that are more specific to the different conditions of the disorder.

Depression has been understood and evaluated based on both categorical and dimensional models. The categorical approach assumes that individual differences are due to the existence of latent classes, representing qualitatively distinct groups; the dimensional approach, on the other hand, assumes that differences reflect levels in a continuum of depression (Clack \& Ward, 2019). These models are not necessarily exclusive. Categorical diagnostic models seem necessary to define the existence of disorders, whereas dimensional models may contribute to more specific interventions, as they consider the frequency, intensity, and duration of the signs and symptoms. Testing these competing models - categorical and dimensional - and discussing the different types of structure helps to deepen the knowledge of the phenomenon.

Latent class analysis allows us to explore the population heterogeneity of depression. Similar to factor analysis, latent class analysis seeks to associate an unobserved variable with a set of observed behaviors. Unlike factor analysis, however, the classes are estimated as categorical profiles. Thus, analyzing measures based on latent classes can help resolve the controversy over whether the best latent structure for depression is dimensional, categorical, or perhaps a combination of both (Ten Have et al., 2016). If depression occurs in discrete classes of individuals, it is possible for each class of patients to require a different psychosocial or drug intervention (Lamers et al., 2010). Furthermore, factor models usually assume a normal distribution of the latent variable (or at least a distribution known a priori), which does not occur in latent class analysis (Muthén, 2002). It is questionable whether the latent phenomenon of depression is indeed normally distributed, as its prevalence equals to about $5 \%$ of the population (WHO, 2017). Models that relax assumptions like these can be valuable to understand and to evaluate mental disorders.

Clusters and latent classes of depression have been reported in several studies. Considering the symptoms described in the DSM, and others not contained in this manual, Li et al. (2014) evaluated more than 6,000 women with recurrent major depressive disorder (MDD). They found three solid profiles, including one with severe symptoms, one atypical, and one non-suicidal. Similarly, Lamers et al. (2010) also evaluated more than 800 participants with MDD, finding three major classes: one with symptoms of severe melancholia, severe atypical, and moderate severity. In another study, Guidi et al. (2011) evidenced two clusters in 198 patients diagnosed with depression; the first consisting of somatic depressive symptoms and the second of anxious/irritable depression. Using Baptista's Depression Scale-Youth Version, composed of 27 self-reported items, Baptista, Cunha e Hauck-Filho (2019) found five latent classes with different compositions of positive affectivity, negative affectivity and suicidal ideation, in a mixed sample of children and adolescents. In these, and other studies in the field, groups or classes tend to represent different levels of typical symptoms, which underscores the ambiguity of the latent structure of the phenomenon.

Taxometric analysis is an ideal method for situations in which categorical and dimensional models coexist in the same phenomenon. The method was conceived by Meehl (1995) as a rate detection approach, that is, groups of individuals with a structural vulnerability for the development of psychopathologies. The taxometric analysis enables a comparison between the fit of categorical with dimensional concurrent models, indicating which is more appropriate to the empirical data (Ruscio et al., 2018). Although most taxometric studies of depression have shown some convergence for a dimensional model (Guo, Chen, \& Ren, 2014); categorical (Baptista et al., 2019) and ambiguous (Ruscio, Brown, \& Ruscio, 2009) results have also been reported.

In this study, the taxometric method is used in combination with latent class analysis in an attempt to further investigate the latent structure of depression in college students. This is an attempt to replicate previous findings, but using a different and recent instrument, the Baptista Depression Scale - EBADEP (Baptista \& Carvalho, 2018). EBADEP was constructed based on indicators from diagnostic manuals such as DSM-IV-TR, 
ICD 10, descriptors of Beck's Cognitive Theory, and the Behavioral Theory of Depression. The instrument consists of 15 self-reported semantic differential items, each of which consists of two antagonistic sentences, with a five-point scale used to indicate which of the two poles the respondent most identifies with. Several studies based on the Classical Test Theory and Item Response Theory support the reliability and validity of the scale, including its internal structure, convergence with BDI, and diagnostic accuracy (Baptista \& Carvalho, 2018; Baptista, Carvalho, Primi, Oliveira, \& Elhai, 2017).

Another issue on exploring the latent structure of depression is response biases. Previous studies do not seem to have expressed concern with whether the detected classes reflect the structure of depression instead of the influence of bias. One possibility is that response styles may influence how individuals cluster together in latent class analysis (Liu, Conrad, \& Lee, 2017). For example, if a particular group of respondents tends to endorse extreme categories of the response scale, the analysis may indicate one or more classes representing those patterns and not necessarily levels of symptoms. Extreme responses are observed when an individual systematically prefers the lower and upper limits of the response scale (Wetzel, Lüdtke, Zettler, \& Böhnke, 2015). A group of respondents with this characteristic may paradoxically be more likely to endorse both ends of the response scale (e.g., "totally agree" and "totally disagree"). Depression inventories might be more susceptible to bias due the items content about extreme behaviors and feelings (for instance, sadness and hopeless). One way to approach this problem is to test whether the latent classes present an association pattern consistent with an external criterion, for example, the clinical diagnosis of depression. Furthermore, we also aim at exploring the potential influence of extreme response on the latent classes structure of self-reported depression symptoms.

The objective of this study was to assess the latent structure of depression in the Baptista Depression Scaleshort (EBADEP-short) by using taxometric analysis and latent class analysis in a sample of college students. We also wanted to investigate whether, and to what extent, extreme responding could be a source of distortion of the latent structure of the EBADEP-short. We specifically aimed at: first, the study combines the advantages of taxometric methods and latent classes in the investigation of the latent structure of depression. Second, the probabilities of endorsement of the depression item categories, within the classes, were inspected in order to certify that they would not reflect extreme response styles. We also addressed the possibility that one or more classes would have a high probability of endorsement of both ends of the response scale, at least for some items. Preferring 1 or 5 in the response scale irrespective of the depression level would be typical of extreme responders (Böckenholt, 2017). Third, the class solutions that were tested were compared in terms of interpretability, assessing for associations in line with an external criterion - the clinical diagnosis.

\section{Method}

\section{Participants}

The participants of this study were 1,137 college students from several higher education institutions in Brazil and over 50 different courses, among which the most frequent are engineering $(n=197)$, computing $(n=100)$, physical education $(n=95)$, nursing $(n=90)$, pharmacy $(n=83)$ and business administration $(n=71)$. Thus, data from students - with varied professional interests and personality characteristicswere evaluated. Ages ranged from 18 to 63 years $($ mean $=$ 26.10 years, $S D=7.32$ ), and the female group represented $48.7 \%$ of the participants. Although this correlational study does not intend to compare clinical groups, self-reported data, on previous diagnosis of mood-related disorders, were also collected. Approximately $89 \%$ of the participants reported that they had never received a depression diagnosed from a health professional, 7\% had been diagnosed in the past, and $4 \%$ reported diagnoses at the time of data collection.

\section{Instruments}

For the assessment of the symptoms associated with depression, the Baptista Depression Scale, short version, EBADEP-short (Baptista \& Carvalho, 2018) was used. The EBADEP-short version focuses on the nine main symptoms described in the DSM-5, while the longer version also assesses symptoms described by psychological theories (cognitive and behavior therapy). A briefer version was used, focusing on descriptive symptoms. This instrument is composed of 15 items disposed in a semantic differential format (in opposing phrases; e.g. "I am feeling happy" versus "I am feeling sad"), and the participants are expected to mark on a five-point scale how close their feelings or behaviors are to one of the extreme ends of the item. The internal consistency of the instrument, estimated in the original study, was equal to 95 , and EBADEP had appropriate sensitivity $(97.5 \%)$ and specificity $(90 \%)$ coefficients.

In addition to the scale, information was collected on the clinical diagnosis of depression. Participants reported whether they had received a diagnosis of depression from a health professional and if they underwent any treatment. The possible answers were: (1) "Yes, in the past"; (2) "yes, I still have the diagnosis and I do the treatment"; (3) "yes, I still have the diagnosis, but I do not get any treatment"; and (4) "no, I have never had this diagnosis". To facilitate the analysis of the data, the variable was dichotomized by collapsing categories 2 and 3, then identifying participants with a current diagnosis of depression.

\section{Procedures}

Data collection. The data were collected collectively in the classroom.

Data analysis. To support the applicability of Latent Class Models, a taxometric analysis was previously performed (Ruscio, Carney, Dever, Pliskin, \& Wang, 2018). Therefore, 
the CCFI (Comparison Curve Fit Index) indicators were analyzed. In order to decide on the number of latent class, the models with different classes were compared using AIC and BIC. In comparing models, lower AICs and BICs values indicate a better fit to the data. Moreover, the entropy of the model and the interpretability of the classes were considered. For all models, the self-reported depression diagnosis was specified as a covariate of latent classes. All the observed variables were declared as categorical, and the parameters were estimated using Maximum Likelihood Robust (MLR), robust to violations of the normal distribution assumption. Due to the large number of parameters, the Integration algorithm was used, implemented in the software Mplus (version 8). To assess the influence of extreme responses, the following steps were taken: (1) Observed item scores were recoded to refle-ct patterns of extreme responses (original responses 1 and 5 were recoded as " 1 ," and responses 2 to 4 were recoded as "0"). (2) We set up a latent bias variable from the recoded scores in the first step. (3) We analyze the relationship between the latent classes and response bias variable. Strong relationships in step 3 were expected, if some latent class grouped participants with high bias scores
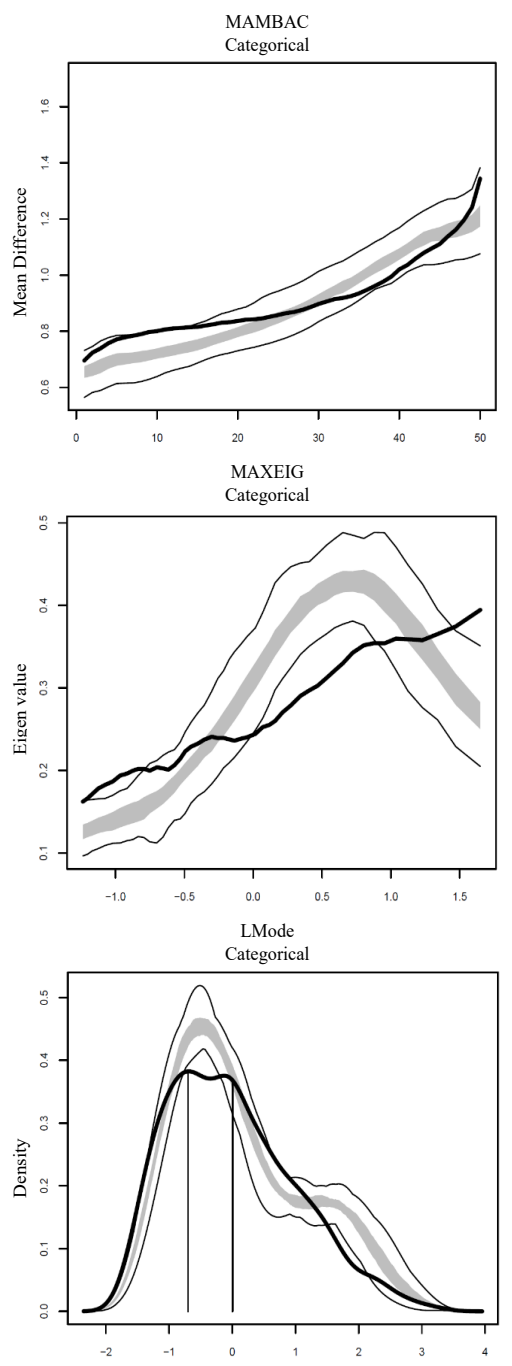

\section{Ethical Considerations}

The research was approved by the Ethics Committee of the University Universo, Rio de Janeiro, Brazil (Process No. 50515715.0.0000.5289)..

\section{Results}

\section{Taxometric Analysis}

To assess the relative fit of categorial (latent class) models of the EBADEP structure, we applied taxometric analysis to the data. Taxometric techniques tend to produce more reliable results when indicators are continuous variables (Ruscio et al., 2018), a criterion that is difficult to meet when the items present only four possible values. In this case, using scores composed by the sum of two or more closely related items can produce more appropriate input indicators. Therefore, five indicators were calculated from sets of three items and these composite scores (not the items) were submitted to taxometric analysis. The results are shown in Figure 1.
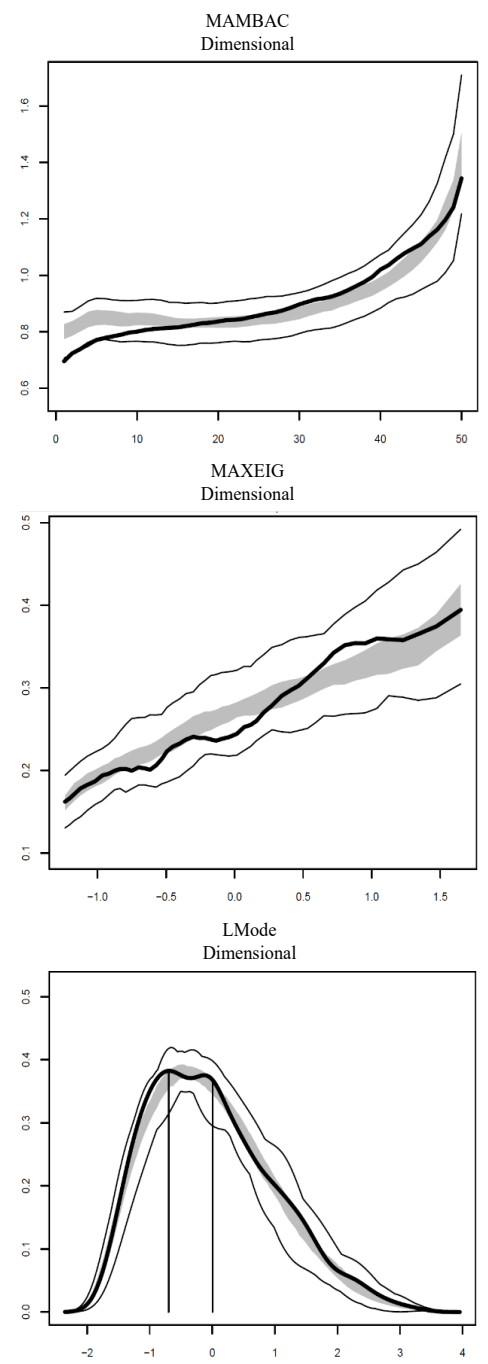

Figure 1. CCFI indicators for dimensional and categorical prototypes of EBADEP. 
The CCFI (Comparison Curve Fit Index) indicators were $0.46,0.39$ and 0.54 for respectively MAMBAC, MAXEIG and LMode (mean $=0.46$ ). These values, within a range of 0.40 to 0.60 , do not permit a clear choice between a dimensional or a latent classification model (Ruscio et al., 2018). In other words, it is plausible to explore latent class models for EBADEP data as well as dimensional models. Moreover, it is possible that latent classes, based on these data, group the individuals based on the intensity of the symptoms. In this way, we continue the exploration of latent classes as a possible structure for the instrument data.

\section{Analysis of Latent Classes}

To decide on the number of latent classes, model fit indices are presented in Table 1. Entropy values indicate how unambiguous the assignment of individuals is to their putative latent classes in each model, with values $>0.85$ indicating acceptable classifications. Nevertheless, an increase in the number of classes was not followed by actual gains in the quality of classifications.

Table 1

Goodness of fit for models with one, two, three and four latent classes

\begin{tabular}{ccccc}
\hline N. Classes & AIC & BIC & Entropy & $\begin{array}{c}\text { \% of cases in class } \\
\text { with lowest n }\end{array}$ \\
\hline 1 & 43169 & 43477 & - & - \\
2 & 38631 & 39231 & 0.87 & $46 \%$ \\
3 & 37839 & 38744 & 0.86 & $28 \%$ \\
4 & 37422 & 38632 & 0.88 & $10 \%$ \\
5 & 37164 & 38678 & 0.86 & $9 \%$ \\
6 & 36986 & 38805 & 0.88 & $8 \%$ \\
7 & Log-likelihood not replicated & \\
\hline
\end{tabular}

The six-class model presented lower fit (upper BIC), therefore it was discarded. The five-class model, despite presenting a better fit when compared to the six-class solution (lower AIC and BIC), did not provide a better interpretability of the probability of belonging to the classes, given the endorsement in different categories of item responses. In this model, two classes presented an indiscriminate pattern of endorsement in the low categories of all items (categories 1 and 2). In the same way, two other classes, whose participants tended to endorse intermediate categories, did not present a clear differentiation pattern of responses either. Consequently, we rejected this model as well.
The four-class model presented the best fit according to the BIC. However, the relationship with the variable diagnosis of depression (odds ratio between 0.33 and 1.35) was low, the patterns of the probability of belonging to the classes were non-interpretable. We consider this last aspect particularly problematic. For example, for item six ("I used to be happier"), classes three and four were more likely to endorse categories one and two, which entails these classes were mainly composed of people with low depressive symptoms. For the same item six, however, participants in class four were more likely to endorse the extreme response categories one and five (see attached table for further details). Therefore, we hypothesized that class four represented people with an extreme response style, especially to items 4 , 6,11 and 14 .

To test this hypothesis, based on these four items supposedly more susceptible to extreme responses, new dichotomous variables were created, in which score 1 was assigned to the endorsement of extreme categories (1 and 5), and 0 to the endorsement of the remaining categories $(2,3$ and 4). Thus, score 1 in these four new variables represents the endorsement of extreme categories only. In the second step, an extreme response factor was estimated (see Greenleaf, 1992), which was regressed on the latent class variable. Thus, it was expected that, if class four were composed of response styles, it should have a significant regression coefficient for the extreme response factor. However, no significant relationship was observed between the probabilities of belonging to the latent classes and the extreme response factor. Thus, the model of four latent classes cannot be interpreted, either theoretically or in terms of response bias, and was, therefore, also abandoned.

Finally, the three-class model achieved a significantly better fit to the data than the two-class model, and its probability patterns of endorsement of response categories were easily interpretable. Thus, this was the model chosen to represent the observed data. The probabilities of endorsement of each class by response category of the items are described in Table 2 (for the sake of easier visualization, only response categories with at least $20 \%$ probability of endorsement by a latent class were kept in the table).

In the three-class model, the first consisted of people who tended to endorse categories between 3 and 5 ; people in class 2 tended to endorse category 1, and class 3 participants tended to endorse intermediate-low categories ( 2 and 3 ). The items 11 and 12 were the ones that best differentiated between class 1 and the others, the content of these items being associated with fatigue and sleep. Additionally, items 1, 2, 3, 7, 8, and 15 also presented distinct endorsement probability patterns between classes, and their contents relative to anxiety, concentration, sadness, low self-efficacy in problem-solving, and feelings of guilt. By contrast, for items 5 and 10, the endorsement patterns were practically indistinct between classes; their contents are extreme and associated with hopelessness and thoughts of suicide. 
Table 2

Probability of endorsement by latent class

\begin{tabular}{|c|c|c|c|c|}
\hline \multirow{2}{*}{ Item } & \multirow{2}{*}{$\begin{array}{l}\text { Response } \\
\text { Category }\end{array}$} & \multicolumn{3}{|c|}{ Latent Classes } \\
\hline & & $\mathrm{C} 1$ & $\mathrm{C} 2$ & $\mathrm{C} 3$ \\
\hline \multirow{3}{*}{ 1. I have been wanting to cry } & 1 & & 0.75 & 0.51 \\
\hline & 4 & 0.27 & & \\
\hline & 5 & 0.26 & & \\
\hline \multirow{4}{*}{ 2. I have been feeling more anguished } & 1 & & 0.70 & \\
\hline & 2 & & 0.25 & 0.38 \\
\hline & 3 & 0.31 & & 0.32 \\
\hline & 4 & 0.32 & & \\
\hline \multirow{4}{*}{ 3. I feel less capable of coping with my problems } & 1 & & 0.71 & 0.29 \\
\hline & 2 & & 0.24 & 0.44 \\
\hline & 3 & 0.33 & & 0.21 \\
\hline & 4 & 0.28 & & \\
\hline \multirow{3}{*}{ 4. I no longer want to do the things I used to like } & 1 & & 0.83 & 0.42 \\
\hline & 2 & 0.23 & & 0.4 \\
\hline & 3 & 0.32 & & \\
\hline \multirow{2}{*}{ 5. I don't believe that things get better } & 1 & 0.37 & 0.88 & 0.64 \\
\hline & 2 & 0.26 & & 0.28 \\
\hline \multirow{4}{*}{ 6. I used to be happier } & 1 & & 0.86 & 0.29 \\
\hline & 2 & & & 0.47 \\
\hline & 3 & 0.34 & & \\
\hline & 1 & & 0.5 & 0.09 \\
\hline \multirow{3}{*}{ 7. I can no longer focus } & 2 & & 0.38 & 0.44 \\
\hline & 3 & 0.29 & & 0.35 \\
\hline & 4 & 0.3 & & \\
\hline \multirow{5}{*}{ 8. I am slower at doing my chores } & 1 & & 0.66 & \\
\hline & 2 & & 0.22 & 0.46 \\
\hline & 3 & 0.28 & & 0.24 \\
\hline & 4 & 0.29 & & \\
\hline & 5 & 0.26 & & \\
\hline \multirow{3}{*}{ 9. My life is getting worse and worse } & 1 & & 0.86 & 0.35 \\
\hline & 2 & 0.29 & & 0.51 \\
\hline & 3 & 0.42 & & \\
\hline \multirow[t]{2}{*}{ 10. I have been thinking it would be better to be dead } & 1 & 0.52 & 0.95 & 0.85 \\
\hline & 1 & & 0.56 & 0.23 \\
\hline \multirow{3}{*}{ 11. I can no longer sleep through the night } & 2 & & 0.24 & 0.28 \\
\hline & 3 & 0.21 & & 0.28 \\
\hline & 5 & 0.25 & & \\
\hline \multirow{4}{*}{ 12. I have been feeling more tired } & 1 & & 0.45 & \\
\hline & 2 & & 0.36 & 0.36 \\
\hline & 3 & & & 0.31 \\
\hline & 5 & 0.45 & & \\
\hline \multirow{3}{*}{ 13. I have slept a lot } & 1 & & 0.58 & 0.27 \\
\hline & 2 & & 0.28 & 0.30 \\
\hline & 3 & 0.38 & & 0.31 \\
\hline \multirow{3}{*}{ 14. I have lost weight without dieting } & 1 & 0.30 & 0.61 & 0.39 \\
\hline & 2 & & & 0.26 \\
\hline & 3 & 0.26 & & .22 \\
\hline \multirow{4}{*}{ 15. I have been feeling guilty for the problems } & 1 & & 0.57 & \\
\hline & 2 & & 0.29 & 0.33 \\
\hline & 3 & 0.25 & & 0.30 \\
\hline & 5 & 0.30 & & \\
\hline Class Probabilities & & 0.28 & 0.28 & 0.44 \\
\hline Odds Ratio (Criterion: self-reported diagnosis of depression) & & 4.14 & & 1.53 \\
\hline Participants with depression diagnostic $(n)$ & & 28 & 7 & 16 \\
\hline
\end{tabular}

Moreover, it can be observed that, even with little endorsement of high categories, the individuals in the first class tended to express symptoms of suicidal thoughts, crying, anguish, negativity towards life, guilt and inability to face problems more intensely. Class two-individuals with a low probability of endorsement in items with negative semantics - exhibited a willingness to perform pleasurable activities, happiness, hope, and positivity. Finally, class three presented intermediate levels of endorsement mainly in the items related to fatigue, concentration, psychomotor slowness, and concentration.

In addition to the structure of the items, we tried to evaluate if the latent classes would be associated with the external criterion of diagnosis of depression. We emphasize that, to collect this data, participants were instructed to indicate the diagnosis only if it was reported by a healthcare 
professional. Participants diagnosed with depression were four times more likely to belong to the first latent class than to the second class (odds ratio $=4.14$ ).

\section{Discussion}

The aim of this study was to investigate the latent class structure of EBADEP, a screening instrument for depressive symptoms, built on diagnostic manuals and cognitive and behavioral theories of depression. The main results are three. First, the mean CCFI of the taxometric analysis was in the range considered ambiguous by Ruscio et al. (2018). Second, a three-class solution resulted interpretable and less biased by potential extreme response bias than concurrent representations of the data. Third, the external criterion of diagnosis of depression discriminated the latent classes.

Regarding the results of the taxonomic analysis of EBADEP, the indicators were inconclusive, which shows that the scale can be structured both in the dimensional and categorical form. Baptista et al. (2019) also found similar results. These investigators looked at a sample of 2700 Brazilian youths from different groups (schoolchildren, clinical, sheltered and in conflict with the law), and CCFI indicators ranged from 0.44 to 0.55 , which indicated ambiguity in pointing to a simple dimensional or categorical model as representing the latent structure of the data. Therefore, the results of our study corroborate the previous study, both with large samples, different age, and diagnostic characteristics. Thus, EBADEP may be useful, even in screening, by providing information on the possibility of an examinee being positive for the diagnosis and yet varying in the intensity of the symptoms measured.

Regarding latent class analyses, the results presented here seem to be close to Li et al. (2014), who suggested three latent classes in diagnosed patients, that is, one with more severe individuals, one with atypical symptoms and the third class with milder symptoms and absence of suicidal ideation. However, Ulbricht, Chrysanthopoulou, Levin, and Lapane (2018) conducted a systematic review including 24 studies of latent classes of depression symptoms. On the one hand, the most common solution was a three-class model, with classes often reflecting symptoms severity consistent with our results. On the other hand, Ulbricht et al. also reported that solutions in the reviewed studies ranged from 2 to 7 latent classes, and that classes of depression sometimes might reflect atypical depressive manifestations and melancholia. Therefore, we cannot generalize the classes we found as general model of depression in Brazil.

In this study, we observed that class one grouped people with greater depressive symptoms. The symptoms that best differentiated this class from the others were those more descriptive of a depressive episode, such as sadness, crying, anhedonia, guilt, helplessness/hopelessness, inability to face problems, and pessimistic view of life (Beck, Rush, Shaw, \& Emery, 1979). This result also supports the discriminative capacity of the items for a possible depression screening.
Class two, represented by individuals most likely to endorse positive items, comprised people considered healthy. The items that most differentiated this class from the others were positive in their content, namely, indicating volition and hope for the future. Additionally, participants in this class had virtually no evidence of suicidal thoughts. Therefore, we conclude that, in this sample, the perception of a positive future and vitality describes a protective profile of depression, beyond other aspects such as sleep, fatigue, and guilt.

Finally, class three individuals present intermediate intensity of fatigue, tiredness, slowness and sleep symptoms. It is important to recall that these symptoms are nonspecific of depression and may be a part of other broad diagnoses, such as Generalized Anxiety Disorder. However, alterations in appetite, weight, and sleep have been used as indicators of latent classes of depression in other studies as well, as these symptoms are relatively common among young individuals, especially adolescents (Rice et al., 2019). Moreover, the literature on network models has demonstrated that these vegetative symptoms constitute a kind of link (or nodes) with symptoms of other mental disorders (Beard et al., 2016; Schmittmann et al., 2013). For example, sleeping problems can induce fatigue and lack of concentration, which, in turn, trigger symptoms of mood and anhedonia. Many individuals in this class, however, may be those referred to as underdiagnosed in a categorical or sub-syndrome perspective and should be evaluated in a more in-depth way (Pelletier et al., 2017; Solomon et al., 2001).

This research also sought to investigate the possible influence of response biases in the composition of latent classes. The model with four classes fitted the data better than the threeclass model we decided to retain. Nevertheless, a cautious inspection of this four-class representation revealed that one of the classes lacked theoretical support as it rather reflected the possible presence of an extreme response style, which made the model spurious and its interpretation questionable. This result illustrates the importance of researchers screening their data for the presence of systematic residual variance, which may distort the latent class solution.

The diagnostic criterion for depression helped differentiate latent classes. Participants with a diagnosis of depression were more likely to belong to the first latent class, whose effect size was strong. For the third class, composed of participants with intermediate levels of symptoms, the effect of the diagnosis was smaller, although also discriminative. The classification of depression cases was not perfect, that is, not all were included in the first class. Most of these cases were more likely to belong to the first class. This result points to a latent model with high sensitivity but less specificity, which is what is expected from a screening instrument, in which the occurrence of false positives is less problematic than false negatives (Vilagut, Forero, Barbaglia, \& Alonso, 2016).

Although the latent class models presented are relevant to understand the depression phenomenon and the internal structure of EBADEP, some limitations of this study should be mentioned. The first limitation concerns the nonclinical and student sample, which produced low probabilities of 
endorsement even in the most pathological class. The second limitation refers to the external criterion of the depression diagnosis having been collected in the self-reported form. Otherwise, a standardized clinical diagnosis assessment could increase the accuracy of this information. On the other hand, even in the self-report, participants were asked to declare the diagnosis only if coming from a health professional. Finally, the method used to test the influence of extreme responses on the latent class composition could be more robust. Ideally, the latent variable of extreme responses should be composed of more indicators with heterogeneous content.

Regardless of the limitations, the study contributes to the deepening of the structure of depression in university students. The latent class analysis has become very popular and useful to examine heterogeneous disorders (Li et al., 2014). Moreover, latent categories can entail practical implications and can help in the diagnosis of depression, in the prediction of prognoses, and in the organization of interventions.

\section{References}

Baptista, M.N., \& Carvalho, L. F. (2018). Diagnostic accuracy of a Brazilian depression self-report measure (EBADEP): Original and short versions. Avaliação Psicológica, 17(4), 484-492. doi:10.15689/ap.2018.1704.8.08

Baptista, M. N., Carvalho, L. F., Primi, R., Oliveira, J. G., \& Elhai, J. D. (2017). Constructing a Common Scale Between Tests of Depression: The use of Item Response Theory for transferring of norms from the BDI to EBADEP-A. Universitas Psychologica, 16(2), 1-11. doi:10.11144/Javeriana.upsy 16-2.ccsb

Baptista, M. N., Cunha, F., \& Hauck-Filho, N. (2019). The latent structure of depression symptoms and suicidal thoughts in Brazilian youths. Journal of Affective Disorder, 254, 90-97. doi:10.1016/j.jad.2019.05.024

Beard, C., Millner, A. J., Forgeard, M. J.C., Fried, E. I., Hsu, K. J., Treadway, M. T., ... Björgvinsson, T. (2016). Network analysis of depression and anxiety symptom relationships in a psychiatric sample. Psychological Medicine, 46(16), 3359-3369. doi:10.1017/S0033291716002300

Beck, A. T., Rush, A. J., Shaw, B. F., \& Emery, G. (1979). Cognitive therapy of depression: A treatment manual. New York, NY: Guilford.

Böckenholt, U. (2017). Measuring response styles in Likert items. Psychological Methods, 22(1), 69-83. doi:10.1037/ met0000106

Clack, S., \& Ward, T. (2019). The classification and explanation of depression. Behaviour Change, 36(1), 41-45. doi:10.1017/bec.2019.4
Fried, E. I., Epskamp, S., Nesse, R. M., Tuerlinckx, F., \& Borsboom, D. (2016). What are "good" depression symptoms? Comparing the centrality of DSM and non-DSM symptoms of depression in a network analysis. Journal of Affective Disorders, 189, 314-320. doi:10.1016/j.jad.2015.09.005

Fried,E.I., \& Nesse, R.M.(2015). Depression is not a consistent syndrome: An investigation of unique symptom patterns in the STAR*D study. Journal of Affective Disorders, 172, 96-102. doi:10.1016/j.jad.2014.10.010

Guidi, J., Fava, G. A., Picardi, A., Porcelli, P., Bellomo, A., Grandi, S., ... Sonino, N. (2011). Subtyping depression in the medically ill by cluster analysis. Journal of Affective Disorders, 132(3), 383-388. doi:10.1016/j.jad.2011.03.004

Guo, F., Chen, Z., \& Ren, F. (2014). The latent structure of depression among Chinese: A taxometric analysis in a nationwide urban sample. PsyCh Journal, 3(4), 234-244. doi:10.1002/pchj.72

Lamers, F., de Jonge, P., Nolen, W. A., Smit, J. H., Zitman, F. G., Beekman, A. T., \& Penninx, B. W. (2010). Identifying depressive subtypes in a large cohort study: Results from the Netherlands Study of Depression and Anxiety (NESDA). Journal of Clinical Psychiatry, 71(12), 1582-1589. doi:10.4088/JCP.09m05398blu

Li, Y., Aggen, S., Shi, S., Gao, J., Li, Y., Tao, M., ... Kendler, K. S. (2014). Subtypes of major depression: Latent class analysis in depressed Han Chinese women. Psychological Medicine, 44(15), 3275-3288. doi:10.1017/S0033291714000749

Liu, M., Conrad, F. G., \& Lee, S. (2017). Comparing acquiescent and extreme response styles in face-to-face and web surveys. Quality \& Quantity, 51, 941-958. doi:10.1007/s11135-016-0320-7

Meehl, P. E. (1995). Bootstraps taxometrics. Solving the classification problem in psychopathology. The American Psychologist, 50(4), 226-275. doi:10.1037//0003066x.50.4.266

Monroe, S.M.,\&Anderson, S.F.(2015).Depression:Theshroud of heterogeneity. Current Directions in Psychological Science, 24(3), 227-231. doi:10.1177/0963721414568342

Muthén, B. O. (2002). Beyond Sem: General latent variable modeling. Behaviormetrika, 29(1), 81-117. doi:10.2333/ bhmk.29.81

Pelletier, L., O’Donnell, S., Dykxhoorn, J., McRae, L., \& Patten, S. B. (2017). Under-diagnosis of mood disorders in Canada. Epidemiology and Psychiatric Sciences, 26(4), 414-423. doi:10.1017/S2045796016000329

Rice, F., Riglin, L., Lomax, T., Souter, E., Potter, R., Smith, D. J., ... Thapar, A. (2019). Adolescent and adult differences in major depression symptom profiles. Journal of Affective Disorders, 243, 175-181. doi:10.1016/j.jad.2018.09.015 
Ruscio, J., Brown, T. A., \& Ruscio, A. M. (2009). A taxometric investigation of DSM-IV major depression in a large outpatient sample: Interpretable structural results depend on the mode of assessment. Assessment, 16(2), 127-144. doi:10.1177/1073191108330065

Ruscio, J., Carney, L. M., Dever, L., Pliskin, M., \& Wang, S. B. (2018). Using the Comparison Curve Fit Index (CCFI) in taxometric analyses: Averaging curves, standard errors, and CCFI profiles. Psychological Assessment, 30(6), 744-754. doi:10.1037/pas0000522

Schmittmann, V. D., Cramer, A. O. J., Waldorp, L. J., Epskamp, S., Kievit, R. A., \& Borsboom, D. (2013). Deconstructing the construct: A network perspective on psychological phenomena. New Ideas in Psychology, 31(1), 43-53. doi:10.1016/j.newideapsych.2011.02.007

Solomon, A., Haaga, D. A. F., \& Arnow, B. A. (2001). Is clinical depression distinct from subthreshold depressive symptoms? A review of the continuity issue in depression research. Journal of Nervous and Mental Disease, 189(8), 498-506. doi:10.1097/00005053-200108000-00002

Ten Have, M., Lamers, F., Wardenaar, K., Beekman, A., de Jonge, P., van Dorsselaer, S., ... de Graaf, R. (2016). The identification of symptom-based subtypes of depression: A nationally representative cohort study. Journal of Affective Disorders, 190, 395-406. doi:10.1016/J.JAD.2015.10.040

Ulbricht, C. M., Chrysanthopoulou, S. A., Levin, L., \& Lapane, K. L. (2018). The use of latent class analysis for identifying subtypes of depression: A systematic review. Psychiatry Research, 266, 228-246. doi:10.1016/j. psychres.2018.03.003

van Lang, N. D. J., Ferdinand, R. F., Ormel, J., \& Verhulst, F. C. (2006). Latent class analysis of anxiety and depressive symptoms of the Youth Self-Report in a general population sample of young adolescents. Behaviour Research and Therapy, 44(6), 849-860. doi:10.1016/j.brat.2005.06.004

Vilagut, G., Forero, C. G., Barbaglia, G., \& Alonso, J. (2016). Screening for depression in the general population with the Center for Epidemiologic Studies Depression (CES-D): A systematic review with metaanalysis. PLoS One, 11(5), e0155431. doi:10.1371/ journal.pone.0155431

Wetzel, E., Lüdtke, O., Zettler, I., \& Böhnke, J. R. (2015). The stability of extreme response style and acquiescence over 8 years. Assessment, 23(3), 279-291. doi: $10.1177 / 1073191115583714$

World Health Organization. (2017). Depression and other common mental disorders: Global health estimates. Geneva, Switzerland: WHO.
Zimmerman, M., Ellison, W., Young, D., Chelminski, I., \& Dalrymple, K. (2015). How many different ways do patients meet the diagnostic criteria for major depressive disorder? Comprehensive Psychiatry, 56, 29-34. doi:10.1016/j.comppsych.2014.09.007

Felipe Valentini is a Professor of the Universidade São Francisco, Campinas-SP, Brazil.

Makilim Nunes Baptista is a Professor of the Universidade São Francisco, Campinas-SP, Brazil.

Nelson Hauck Filho is a Professor of the Universidade São Francisco, Campinas-SP, Brazil.

\section{Authors' Contribution:}

All authors made substantial contributions to the conception and design of this study, to data analysis and interpretation, and to the manuscript revision and approval of the final version. All the authors assume public responsibility for content of the manuscript.

Associate Editor:

Susana Maria Gonçalves Coimbra

Received: Nov. 01, 2019

1st Revision: Dec. 11, 2020

2nd Revision: Mar. 30, 2021

Approved: Apr. 24, 2021

How to cite this article:

Valentini, F., Baptista, M. N., \& Hauck-Filho, N. (2021). Typological profiles of depression of college students: Latent classes and controlling for response bias of the Baptista Depression Short-Scale (EBADEP-short). Paidéia (Ribeirão Preto), 31, e3129. doi:https://doi.org/10.1590/1982-4327e3129 